\title{
Realization of integrative technologies of physical culture and sports in the institutions of state support of childhood of Russia
}

\author{
Elena Bayer ${ }^{1, *}$, Nikolai Kuryanov ${ }^{1}$, Narine Grigoryan ${ }^{2}$, and Anna Grishina ${ }^{3}$ \\ ${ }^{1}$ Don State Technical University, 344003, Gagarin sq., 1, Rostov-on-Don, Russia \\ ${ }^{2}$ Federal State-Funded Educational Institution of Higher Professional Education Rostov state medical \\ University, 344003, Nakhichevansky lane, 29, Rostov-on-Don, Russia \\ ${ }^{3}$ Southern Federal University, 344003, Bolshaya Sadovaya str., 105/42, Rostov-on-don, Russia
}

\begin{abstract}
Annotation. The high demand of the Russian state for training effective specialists in the field of politics, Economics, education, medicine, qualified engineers and workers obliges us scientists and practitioners to think about developing productive mechanisms, technologies and programs for the formation and development of a highly qualified personality in demand by modern society. Taking into account the strategic objectives of preparing orphaned children for independent life, through an effective technology for building the pedagogical process in the institution of state support for children, through theoretical and methodological, practiceoriented and result-based competence stages. The study proves that a consistent, gradual and systematic impact on various areas of the individual increases motivation to acquire knowledge, increases internal and external culture, and creates a space for socialization of the child. A significant role is given to physical culture and sports in the pedagogical process of forming socially demanded personality traits of orphaned children. It is established that in the process of implementing the pedagogical system of forming the resilience of orphaned children, the acquired negative social experience is gradually and consistently replaced, transformed into a resource base for further life in society, and physical health is significantly improved.
\end{abstract}

\section{Introduction}

Theoretical and practice-oriented research by Russian scientists aimed at finding effective pedagogical tools for preparing a viable generation of orphans, actualizes the development of effective models for the formation of a viable personality.

According to the results of the methodological analysis of domestic studies in the field of physical education, the most productive point of view of our domestic scientist P.F. Lesgaft. It was from his progressive position that a new era began in the field of physical education. In his scientific work "Guide to the physical education of schoolchildren" P.F.

\footnotetext{
*Corresponding author: zaluzhnaya.mari@mail.ru
} 
Lesgaft called the erroneous and one-sided teaching of children only motor actions, the development of physical qualities without an educational component [1].

The idea of intensifying the process of searching, obtaining and accumulating knowledge in the field of preparing orphans for independent life by means of physical education is supported by such domestic theoretical scientists as V.K. Balsevich, L.I. Lubysheva, N.I. Ponomarev and others. The innovative sports technologies developed by them and put into practice prove the ability to act in non-standard conditions of the domestic education system. So, in the last decade, V.K. sports technologies have become widespread. Balsevich (sportization), V.I. Stolyarov (Olympic education), L.I. Lubysheva (sports culture of personality), I.V. Manzheley (systematization of pedagogical models of physical education), E.A. Bayer (the formation of the resilience of orphans by means of physical education and sports) and others [2]. We found that the active use of sports activities, health-saving technologies, competitions and elements of sports in the educational process is directly related to the formation of a sports culture of the individual. In turn, the sports culture of a person is identical in its parameters to such a vital characteristic for socialization as vitality [3].

\section{Methods and materials of the study}

Analysis of medical records for classification as minor health groups on the basis of the order of the Ministry of Health of the Russian Federation dated 10.08.2017 N514n "On the procedure for conducting preventive medical examinations of minors" (as amended on 13.06.2019 No. 396n)

To build an effective model of the educational process, it is advisable to determine the main stages of the study. At the initial stage, it is necessary to carry out a theoretical analysis of the process of maintaining and strengthening human health. We consider the main purpose of the work of institutions to be the formation of a child who should be ready to use the internal capabilities of his body to manage adaptive resources that provide resistance to various life stress factors. It is important not only to create a caring attitude towards their health in orphans, but also through the properly organized physical education in the conditions of the institution of state support for childhood to purposefully improve the physical and mental properties of the person. This process should be carried out as part of a deterministic approach using the principle of nature-building, that is, relying on the natural abilities and strength of the pupil, provided that the formation process is aligned with the natural stages of the child's development, as well as using natural means of physical education.

The second stage is related to the actualization of the potential of the system we have created for building the resilience of orphans and a fundamentally new approach to the process of "providing educational services" in the context of state support institutions for children, since from 2014 to the present, orphans live in institutions and receive educational services . Incidentally, the status of children living in institutions of state support for childhood has changed in some way. Some of the children, and their number is increasing, are now under state supervision, and the length of their stay has been significantly reduced this is a period of 1 to 6 months. The main task is to prepare the children at this time either for returning to the blood family, or for adaptation in a new foster family [4]. The content of this stage is the productive work of the entire teaching staff of the institution on the timely correction of the physical and psychological health of the child, "receiving services under supervision." It is at this stage that it is necessary to include the child in the educational process as an equal participant.

As our practice has shown, the social activity of orphans, especially in sports, can become significant for themselves, for this they must have a developed sense of personality 
and understanding of their responsibility in the immediate social environment. Taking into account the age and potential of the child, we strive for a limited time to teach him how to use his acquired health resources, to create motivation for getting an education, to aim at getting a sought after profession, and also to develop a personal need for a sports lifestyle. Significant socializing effect is incorporated in sportsization technology tested in the conditions of the Azov Center for Helping Children.

The third stage is carried out directly during the period of temporary stay of the child in the institution where he is under state supervision. Therefore, at this stage, it is necessary to adjust the structural model of a resilient personality, taking into account the target indicators demanded by society. The task of establishing an important basis - the moralvolitional sphere of the personality, which will allow in the future to unhinderedly reach the necessary level of standards and relevant norms, meet the model requirements set by society for young citizens, comes to the fore. For this, it is necessary not only to correct, but also to update scientific and practical technologies in the field of physical culture and sports, as well as to select the best of those that have passed positive testing in the conditions of the experiment. To this end, the implementation of an effective, in a new format, pedagogical work of the institution of state support for childhood will require the adoption of a number of measures:

1. development of programs in accordance with the objectives of pedagogical correction and development of physical, volitional and moral qualities using physical culture and sports [5];

2. building an algorithm for applying a personality-oriented approach to each adolescent in a center for children's help, assigning a significant mentor among adult athletes of the Russian level with high performance in sports to pupils [6], [7];

3. preparation of universal diagnostic tools for the control and self-control of adolescents in the formation of vitality and responsible attitude to their health [8];

4. development of ideal personality models, including those oriented to the living conditions of a person and the real environment of a teenager (school, center, sports sections, etc.) [9];

5. creating a favourable health environment through the involvement of a teenager in physical culture and sports activities; control over organized sports activities; teaching the basics of behaviour in life situations of risk (defeat, betrayal), as well as the formation of socially significant relationships (friendship, love, responsibility for the family) [10].

Results and discussions: the significant health-saving and pedagogical effect is carried by the idea of forming the resilience of orphans by means of physical education and sports in the conditions of state support institutions for childhood. The embodiment of this goal can significantly improve the system of preparing orphans for independent living. As our preliminary studies have shown, if we consistently, gradually and systematically act not only on the biological (physical) sphere, but also develop mental, aesthetic, moral resources, there is a gradual building up of the motivation of the personality of an orphan child to gain knowledge, increase internal (personal) and external (behavioural) culture [11], [12].

It is important that the use of special approaches using physical culture and sports technologies and personal growth methods allows all orphans to be involved in a variety of sports activities for three main types of programs: sports training (for the chosen sport), general physical training, and adaptive fitness training. The uniqueness of this approach lies in the fact that each pupil, due to the prompt application of diagnostic techniques, receives up-to-date information about their achievements, potential opportunities and abilities, and also has the ability to freely change the type of sports or physical education activities.

To normatively consolidate the existing capabilities of the pupils, we have developed: "Regulations on the sports club", "Regulations on the sports team" and other information 
materials that are widely available. It is important to emphasize that the development of the values of physical culture and sports takes place in the process of sports and creates a space for the socialization of the child, since it is carried out in vivo in the development of significant personality traits (vitality, responsibility, etc.) with strict regulation of the performance of a set of sports exercises in collective and individual forms. Thus, the principle of unity, cooperation and "healthy" rivalry is implemented to achieve the goal.

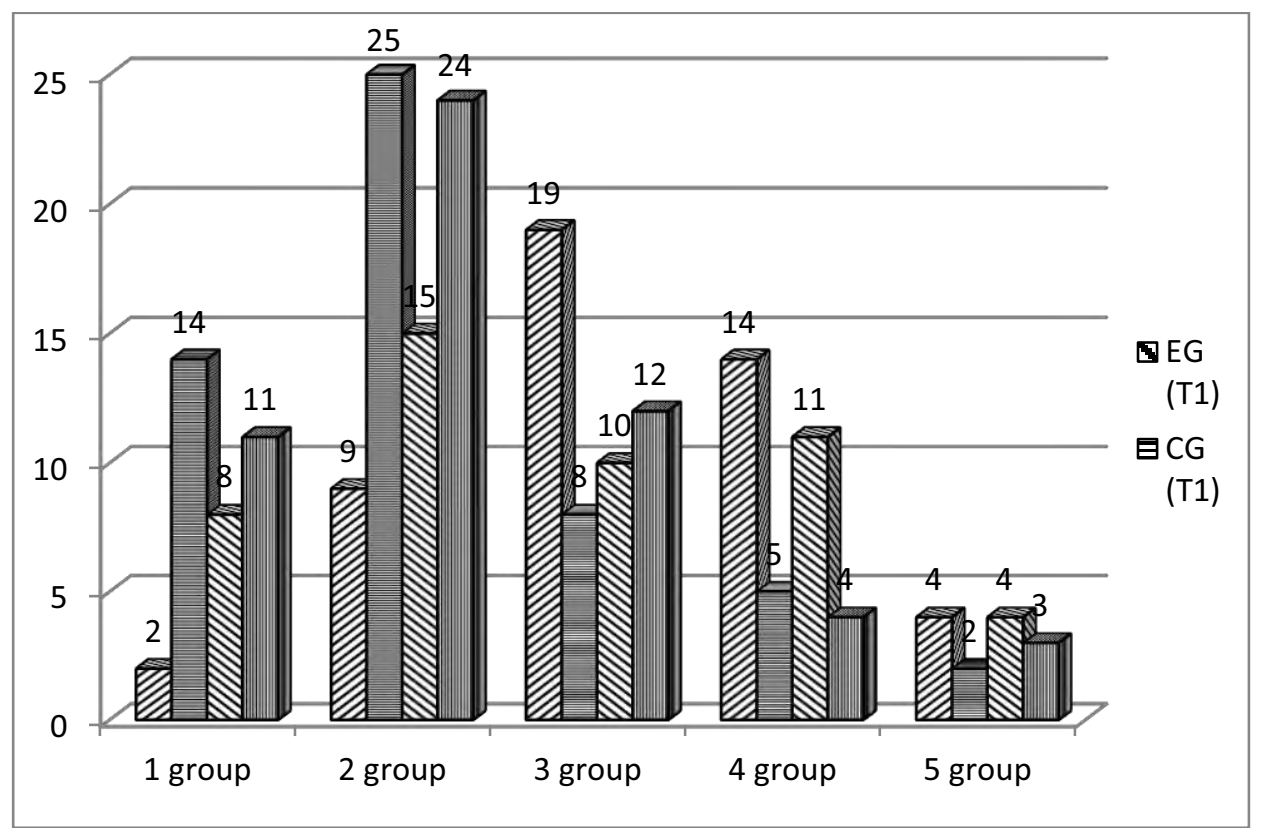

Fig. 1. The health group of orphans in the EG and CG before the experiment (T1) and after the experiment (T2)

From figure 1 and table 1 it is seen that at the final stage of the experiment (T2), there is a positive dynamics of the health indicator of the subjects. So the number of "healthy" children making up the first group increased to 8 people, the 2nd group amounted to 15 people. It was possible to reduce the value of the 4th group of health to 11 people and to stabilize the 5th group; not a single child was assigned the status of a disabled person. The data confirm the medical records of orphans, which analyzed the frequency of diseases in the EG and CG for the period 2019 and 2020 [Table 1]

Table 1. Frequency of diseases of pupils (boys and girls) of Azov (EG) and Shakhty (KG) for 20192020

\begin{tabular}{|l|l|l|c|c|}
\hline \multirow{2}{*}{ Diseases } & \multicolumn{2}{|c|}{ Azov (EG) } & \multicolumn{2}{c|}{ Shakhty (KG) } \\
\cline { 2 - 5 } & $\mathbf{2 0 1 9}$ & $\mathbf{2 0 2 0}$ & $\mathbf{2 0 1 9}$ & $\mathbf{2 0 2 0}$ \\
\hline Infectious and parasitic & 11 & 8 & 0 & 0 \\
\hline $\begin{array}{l}\text { Blood and blood-forming } \\
\text { organs }\end{array}$ & 2 & 1 & 0 & 0 \\
\hline Endocrine system & 24 & 3 & 4 & 3 \\
\hline Nervous system & 14 & 4 & 11 & 5 \\
\hline Organ of vision & 2 & 7 & 18 & 17 \\
\hline Organ of hearing & 0 & 1 & 0 & 0 \\
\hline Of the digestive system & 13 & 7 & 1 & 5 \\
\hline Urogenital system & 0 & 6 & 2 & 7 \\
\hline
\end{tabular}




\begin{tabular}{|l|l|l|l|l|} 
Cardiovascular system & 0 & 0 & 5 & 6 \\
\hline Musculoskeletal system & 0 & 0 & 15 & 14 \\
\hline Mental retardation & 0 & 0 & 6 & 8 \\
\hline Mental disorder & 0 & 0 & 4 & 7 \\
\hline Neoplasms & 0 & 0 & 2 & 3 \\
\hline $\begin{array}{l}\text { Congenital abnormalities } \\
\text { (malformations) }\end{array}$ & 4 & 3 & 0 & 2 \\
\hline Injuries & 5 & 0 & 0 & 0 \\
\hline Other diseases & 8 & 0 & 0 & 0 \\
\hline Respiratory & 87 & 52 & 5 & 12 \\
\hline
\end{tabular}

The frequency of diseases of pupils (boys and girls)

\section{Azov (EG) and Shakhty (KG) for 2019-2020}

An analysis of the results obtained when solving the problem of determining the health group of the physical block of vitality of orphans, confirmed that the technology of sports physical education (on the basis of the Olympus club of the Azov Children's Aid Center) has a positive effect on the frequency of diseases of orphans.

It should be noted that the transition of the Center for Assistance to Children to a new format of the pedagogical system for building the resilience of orphans occurred in 2019. It is this year that we consider to be the beginning of the implementation of sportization at the stage of preparing pupils for returning to a blood family or transition to a new foster family, or for adaptation of a graduate to independent life.

In the practical implementation of our pedagogical system of resilience, we, firstly, rely on a specially formed moral-volitional core of the child, and secondly, purposefully "wrap" new model characteristics of vitality on the core using physical culture means in the conditions of the Azov Center for Helping Children [13].

According to this algorithm, a socially adapted graduate of the Center is being trained. The results of an empirical study show that the use of specially designed innovative technology of sportization must be linked with the use of the environmental approach as a way to build the educational process with an active impact on each person directly. It is important to understand that social disadaptation and pedagogical neglect are the most urgent problems of orphans, due to the negative experience they acquired earlier [14-15].

In our experiment on the basis of the Azov Center for Children's Help, we examined the scientific hypothesis that the developed system for the formation of resilience by means of sporting gradually and consistently replaces the previously acquired negative experience of orphans, while simultaneously adjusting its psychological and physical health parameters according to a specially developed program. For the age of 3-18 years, the program intentionally laid out components aimed at developing a structural model for the formation of the moral-volitional qualities of the personality demanded by society [16].

This process was built through the implementation of a system of specially selected physical exercises, which simultaneously serves as a mechanism for the timely correction and development of personal qualities of a previously deviant and delinquent teenager, forming socially significant traits such as discipline, determination, perseverance, independence, initiative, perseverance, honesty, mutual assistance and mutual respect.

At the final stage of the implementation of the pedagogical system in the context of a help center for children to prepare each child for an independent life, the task is to ensure a positive attitude of the pupils to the values of sports, to complete the process of forming the foundations of vitality and a responsible attitude to their health, thus overcoming an established opinion about what is characteristic of orphans passive adaptation to the environment. At this stage, the pupils are able to demonstrate a sustainable ability to self- 
development, independence, activity and competitiveness, which should help to increase the level of formation of model characteristics of the resilience of orphans.

At the same time, in order to intensify the process of forming viable pupils using healthsaving technologies, the necessary condition is the training of pedagogical personnel with special knowledge in the field of social pedagogy and methodological skills [17].

Such training is achieved only if innovative restructuring of the educational process of future teachers, taking into account the specifics of working with deviant children and members of their families [18].

The mandatory components of the training of such specialists should be practical orientation, integration of scientific approaches and their active implementation, specific psychophysiological knowledge, as well as effective social management skills that allow complex modification of the ecology of modern families.

Today, the format of training that meets the above conditions is gradually being introduced into the practice of the most progressive universities - this is the opening of basic departments in organizations of a social orientation, which allow young specialists to develop skills of their application in practice already at the stage of obtaining new knowledge [19].

A striking example of an innovative approach to the training of highly qualified pedagogical personnel capable of solving state tasks to overcome the threats of growing social orphanhood, family well-being, child crime and neglect is the opening of the Don State Technical University, a reference multidisciplinary university in the Rostov region, the department of Social Pedagogy at the faculty "Psychology, pedagogy and defectology".

To implement a practice-oriented approach, to develop and implement modern healthsaving technologies in the training of specialists, the department was created as part of a social partnership with the regional Ministry of Education on the basis of the GKUSO RO "Azov Center for Children's Help" (director - Dr. Bayer E.A.). The choice of the location of the department is not accidental - the Center is a federal innovation platform of the Russian Academy of Education, it is one of the leading institutions in the region, a regional methodological resource center for the education of deviant adolescents and social and pedagogical assistance to families of the "risk group" [20].

The department's activities are aimed at organizing, coordinating and developing the system of social and pedagogical education in the region, training professional personnel: specialists of guardianship and guardianship agencies, commissions for minors and protecting their rights, family education specialists, social and psychological support of foster families, as well as specialists in the field of physical education and sports. The functioning of the department of social pedagogy on the basis of the GKUSO RO of the Azov help center for children is focused on radical changes in the system of teacher education, namely it involves a shift in emphasis on pedagogical practice - involving educational institutions, health care and social organizations in the region as internship sites for future specialists.

The creation of the department will positively affect the improvement of the quality of state assistance to children and families of social risk groups, create conditions for the active introduction of modern pedagogical and psychological technologies in the social sphere of the region, and most importantly, it will allow choosing new approaches to the formation of socially significant qualities of deviant pupils with the help of caring and professionally trained young people - future effective professionals.

All these allows to look in a new angle at the views of scientific predecessors, including P.F. Lesgaft, who foresaw the significant role of physical culture in the pedagogical process of forming socially significant qualities of the personality of an orphaned child, in fact - a deviant teenager. These ideas today not only do not lose their relevance, but are also being 
transformed into more popular and successfully implemented in institutions of state support for childhood, in the process of educating viable members of civil society.

\section{Conclusions}

1. In the course of intensification of the search, acquisition and accumulation of knowledge, skills and professional competence of specialists of state support institutions for children, special attention should be paid to innovative technologies of health saving in the formation of personal qualities of vitality of orphans by means of physical culture and sports. For these purposes, we recommend the use of methods and forms already tested in practice, such as: sports physical education, a sports team of a child care center, a sports club, Olympic education, etc.

2. During selecting innovative technologies, it is important to use process-meaningful constructions, pedagogical, psychological and health-improving models of education with a set of specific diagnostic tools. As recommended theoretical and methodological innovations in the field of targeted educational services, physical culture and sports are offered in the conditions of state support institutions for childhood.

3. The resolution of the practical problems of institutions of state support for childhood is seen in research and methodological work on the implementation of integrative technologies of physical education and sports. The condition for the implementation of innovative methods in the practice of institutions is the training of unique specialists in the higher education system through the integration of physical education and sports methods, on the one hand, and social pedagogy, on the other.

4. The categorical apparatus of general pedagogy is supplemented by such concepts as "the resilience of orphans", "sportization", "integrative technologies of physical education and sports", "sportized physical education of orphans", "specialist in physical education and sports in social pedagogy "[6.7].

As a prospect for further research, it can be pointed out that the use of new approaches to the training of specialists working with deviant and delinquent children necessitates the development and transformation of a variety of academic disciplines at a qualitative level, opening up new areas and profiles of higher education training programs taking into account the demanded integration of social and health-saving technology.

Design modules and constructions of the proposed approach, subject to their scaling, will allow creating effective models for constructing innovative educational disciplines in the system of training teachers; in turn, the implementation of best practices and promising integrative technologies - wellness-adaptive, socially-oriented, personality-oriented and sports-reactionary will allow reaching a new level of training of teaching staff for effective work with children and families of social risk groups.

\section{References}

1. G. Aarons, A. Green, L. Palinkas, Shannon R Self-Brown, D. Whitaker, J. Lutzker, Jane F. Silovsky, Debra B. Hecht, M. Chaffin, Implementation Science, 7, 32 (2012) DOI: $10.1186 / 1748-5908-7-32$

2. K. Bernard, M. Dozier, J. Bick, E. Lewis-Morrarty, O. Lindheim, E. Carlson, Child Development, 83(2), 623-636 (2012)

3. E. Bayer, S. Avakov, N. Grigoryan, R. Aroutyunyan, SHS Web of Conferences Trends in the Development of Psycho-Pedagogical Education in the Conditions of Transitional Society (ICTDPP-2019), 70, 4 (2019) doi.org/10.1051/shsconf/20197001003

4. S. Johnson, J. Pryce, Child Welfare, 92(3), 9-25 (2013) 
5. G. Breakwell, Papers on Social Representations, 19 (2010)

6. N. Tottenham, T. A. Hare, A. Millner, T. Gilhooly, J. D. Zevin, B.J. Casey, Developmental Science, 14(2), 190-204 (2011) doi.org/10.1111/j.14677687.2010.00971.x

7. M. Hardy, J. Koprowska, E. McDermott, P. Walton, M. Webber, Mental Health Social Work: The Art and Science of Practice, 448, (2019)

8. J. M. Brown, Journal of Family Therapy, 37(3), 286-307 (2015)

9. B. Pakizegi, USA International Journal of Humanities and Social Science, 2(1), 173188 (2012)

10. B. A. Akin, S. A. Bryson, T. McDonald, S. Walker, Child Welfare, 91, 79-101 (2012)

11. J. Koprowska, Exeter: Learning Matters, 213 (London, 2013)

12. G. A. Bonanno, M. Westphal, A. D. Mancini, Annual Review of Clinical Psychology, 7, 511-535 (2011) DOI: org/10.1146/annurev-clinpsy-032210-104526

13. Hans de Wit, SFU Educational Review, 12(3), 9-17 (2019) DOI: https://doi.org/10.21810/sfuer.v12i3.1036

14. M. Chaffin, B. Funderburk, D. Bard, L.A. Valle, \& R. Gurwitch, R.. Journal of Consulting and Clinical Psychology, 79(1), 84-95 (2011) DOI: 10.1037/a0021227

15. S. E. U. Kerns, S. Dorsey, E.W. Trupin, L. Berliner, Report on Emotional and Behavioral Disorders inYouth, 10, 30-38 (2010) DOI: 10.1177/106342669500300201 